\title{
Deficits in Radial Arm Maze Performance in Kindled Rats: Evidence for Long-Lasting Memory Dysfunction Induced by Repeated Brief Seizures
}

\author{
Thomas Sutula, Suzanne Lauersdorf, Michael Lynch, Caroline Jurgella, and Austin Woodard \\ Departments of Neurology and Anatomy, and the Neuroscience Training Program, University of Wisconsin, \\ Madison, Wisconsin
}

\begin{abstract}
Repeated activation of neural pathways by kindling induces brief seizures, permanent increases in seizure susceptibility, neuronal loss in the hippocampus, and mossy fiber sprouting in the dentate gyrus. Because kindling induces permanent cellular alterations in hippocampal pathways that have been implicated in memory, it was of interest to determine if kindling also induces long-lasting impairments in a spatial memory task in rats. In this study, the effects of kindling on memory were investigated by assessing kindled rats in a radial arm maze behavior that is impaired by hippocampal damage. Kindled rats studied at 1 month after the last of 30-134 evoked generalized tonic-clonic seizures acquired competence in the performance of the radial arm maze task at a rate that was indistinguishable from agematched normal controls, but demonstrated a deficit in the ability to repeat the task on consecutive days. The repetition deficit was not observed in rats that experienced three afterdischarges or three generalized tonic-clonic seizures, and the severity of the deficit varied directly with the number of evoked kindled seizures. Repeated brief seizures evoked by kindling induced a long-lasting deficit in a radial arm maze task that is a rodent model of memory. The observation of a long-lasting deficit in radial arm maze performance in kindled rats suggests that the cellular alterations induced in the hippocampus by seizures could contribute to the memory dysfunction in human epilepsy.
\end{abstract}

[Key words:hippocampus, dentate gyrus, limbic, epilepsy, cognition, seizures, kindling, memory]

The hippocampal formation has been implicated in human learning and memory by clinical studies in people with amnestic syndromes. Evidence for the role of medial temporal lobe structures in human memory includes the pioneering observation that bilateral medial temporal lobe resection in patient H.M. produced severe chronic anterograde amnesia with little change in other cognitive functions (Scoville and Milncr, 1957). Subsequent studies of human amnesia in people with focal hippocampal lesions have also implicated the hippocampus and its specific subregions in learning and memory (Squire et al., 1990; ZolaMorgan et al., 1989).

Received Apr. 4, 1995; revised July 20, 1995; accepted July 26, 1995.

This work was supported by NS25020 and the Klingenstein Fund. We appreciate the helpful comments of Ann Kelly and Charles Matthews.

Correspondence should be addressed to T. Sutula, Department of Neurology, $\mathrm{H} 6 / 5 \%$, University of Wisconsin, Madison, WI 53792.

Copyright $(1995$ Society for Neuroscience $0270-6474 / 95 / 158295-07 \$ 05.00 / 0$
The relationship between the hippocampal formation and memory has been systematically investigated by experimental studies in nonhuman primates with surgically circumscribed lesions (Zola-Morgan et al., 1989; Squirc and Zola-Morgan, 1991). In these studies, damage to the hippocampus and adjacent cortex produced a deficit in visual recognition tasks such as delayed nonmatch to sample. These observations supported the view that the hippocampus and adjacent structures in the medial temporal lobe are critical for entering new factual information into long-term memory (Zola-Morgan and Squire, 1990), and are components of a "medial temporal lobe memory system" (Squire and Zola-Morgan, 1991; Squire, 1992; Zola-Morgan and Squire, 1993; Treves and Rolls, 1994).

Experimental studies in rodents have implicated the hippocampus in spatial learning and memory (Jarrard, 1993). Hippocampal pyramidal cells in rats discharge at specific locations in the environment (Muller et al., 1987), and maintain their receptive field in the absence of spatial and visual cues (Quirk et al., 1990). These observations have suggested that the hippocampus may perform spatial computations by means of a cognitive map (O'Keefe and Nadel, 1978; O'Keefe, 1990). The hippocampus may also play a role in nonspatial learning such as odor discrimination (Eichenbaum et al., 1990).

Hippocampal lesions in rats produce an impairment in ability to perform tasks that involve place learning and spatial navigation, such as the radial arm maze and the Morris water maze (O'Keefe and Nadel, 1978; Jarrard, 1980; Morris et al., 1982). On the basis of the behavioral effects of experimental hippocampal lesions in both primates and rodents (Jarrard, 1980, 1993; McNaughton et al., 1989; Moser et al., 1993), pathological processes that induce hippocampal damage may be accompanied by impairments in spatial and other behavioral tasks requiring integrity of the hippocampus and related adjacent limbic cortex. For example, as recent studies in the kindling model of epilepsy have demonstrated that brief repeated seizures induce hippocampal and limbic neuronal loss (Cavazos and Sutula, 1990; Cavazos et al., 1994), kindled rats might be expected to have a deficits in radial arm maze performance.

Kindling has been extensively studied as a model of temporal lobe epilepsy because it induces permanent increases in seizure susceptibility and recurrent spontaneous seizures (Goddard et al., 1969; McNamara, 1986). Kindled seizures are accompanied by neuronal loss in dentate gyrus, hippocampus, and adjacent limbic cortex (Cavazos and Sutula, 1990; Cavazos et al., 1994), and by mossy fiber sprouting and synaptic reorganization in the dentate gyrus (Sutula et al., 1988; Cavazos et al., 1991), which 
progress in parallel with the evolving seizures, and like kindling, are permanent.

The aim of this study was to determine if kindled seizures induce long-term deficits in a radial arm maze learning task that is dependent on integrity of the hippocampus. The ability to learn and repeat a radial arm maze task was evaluated in pairs of age-matched unstimulated rats and kindled rats. Because previous studies have demonstrated that radial arm maze behavior is acutely disrupted by electrical stimulation of hippocampal pathways (Knowlton et al.1985) and seizures (Lopes da Silva et al., 1986; Knowlton et al., 1989; Leung et al., 1990; FeasyTruger et al., 1993), kindled rats were evaluated at 1 month after the last evoked seizure. At this time point, the effects of kindling could be assessed independently of the effects of recent evoked seizure activity.

\section{Materials and Methods}

Surgical procedures. Adult male Sprague-Dawley rats $(250-350 \mathrm{gm})$ were anesthetized with a combination of ketamine $80 \mathrm{mg} / \mathrm{kg}$ i.m. and xylazine $10 \mathrm{mg} / \mathrm{kg}$ i.m., and were stereotaxically implanted with an insulated stainless steel bipolar electrode for stimulation and recording in the olfactory bulb $(9 \mathrm{~mm}$ anterior, $1.2 \mathrm{~mm}$ lateral, $1.8 \mathrm{~mm}$ ventral to bregma). The olfactory bulb was chosen because stimulation of this site rapidly induces kindled seizures, and the potential confounding effects of damage from direct placement of the electrode into the hippocampus could be avoided. After a recovery period of 2 weeks, age-matched pairs of electrode implanted rats were randomly assigned to a group that received kindling stimulation, or to a paired control group that was similarly handled, but did not receive electrical stimulation.

Kindling procedures. The unrestrained awake animals in the kindling group received twice daily kindling stimulation ( $5 \mathrm{~d}$ per week) with a $1 \mathrm{sec}$ train of $62 \mathrm{~Hz}$ biphasic constant current $1.0 \mathrm{msec}$ square wave pulses. The stimulation was delivered at the lowest intensity that evoked an afterdischarge $(\Lambda \mathrm{D})$ according to standard procedures (Cavazos et al., 1994). The electroencephalogram and AD were recorded from the electrode in the olfactory bulb, which could be switched to the stimulator by a digital circuit for the delivery of the kindling stimulation. The evoked behavioral seizures were classified according to standard criteria (Sutula and Steward, 1986). Rats received stimulation until three ADs, or 3, 30, 70-100, or greater than 100 Class V seizures were evoked. Class $V$ seizures are characterized by bilateral tonic-clonic movements and loss of postural tone, and are comparable to partial complex seizures with secondary generalization, which are frequently observed in human temporal lobe epilepsy (McNamara, 1986).

Control procedures. A group of paired age-matched control rats were handled and placed in the recording cage twice daily according to the same protocol, but did not receive stimulation. Each control rat was handled twice daily until its paired kindled rat experienced the assigned number of Class V seizures.

Behavioral testing. After completion of the last kindling stimulation, the kindled rats were treated with a 1 month rest interval. During this interval, the kindled rats were placed into the recording cage and handled twice daily in the same manner as the control rats, but did not receive electrical stimulation. Control rats continued to undergo twice daily handling and placement in the recording cage. After the third week of the rest period, the paired kindled and control rats were weighed and placed on calorie restriction consisting of two pellets of standard rat chow daily to achieve weight reduction to $85-95 \%$ of the initial measured weight. During the last week of the 4 week rest period, each rat also received four raisins daily in order to become familiar with the bait that would be used in subsequent radial arm maze testing. Calorie restriction was continued for the duration of behavioral testing, and each rat was weighed three times per week. The daily food ration was adjusted as necessary to insure that weight was maintained in range of $85-95 \%$ of the initial measurement.

After completion of the 1 month rest interval, behavioral testing in an eight-arm radial maze was performed at the same time each day for $5 \mathrm{~d}$ per week. The design and dimensions of the radial arm maze conformed to specifications in previous studies (Leung et al., 1990). For the duration of the study, the same four arms of the eight-arm radial maze were baited with a raisin, which was hidden from view in a recess at the end of the arm. Each rat was placed in the center of the maze, and was observed for the sequence of arm entries and consumption of the raisins. Criterion performance was defined as consumption of the raisin in all four baited arms during no more than five entries. Rats were removed from the maze after failure to consume the four raisins within $10 \mathrm{~min}$, or after 30 entries without consumption of the bait.

The sequence of entries into baited and unbaited arms of the radial maze was recorded during daily behavioral trials. According to terminology in previous studies (Jarrard, 1980; Lopes da Silva et al., 1986; Leung et al., 1990), entry into an unbaited arm was scored as a reference error. Reentry into a baited arm was scored as a working error. Reentry into an unbaited arm was scored as a reference and a working error. Completion of the behavioral task was defined as achievement of criterion performance on each of five consecutive daily trials.

After achievement of criterion performance on 5 consecutive days, the rats continued daily behavioral trials for 1 additional week, and were then evaluated for recall or memory of the correct baited arms by an additional testing procedure. In this additional testing procedure, all arms of the radial maze were unbaited. Each rat was then placed in the center of the maze, and the ratio of entries into previously baited and unbaited arms was recorded during a $10 \mathrm{~min}$ period of observation.

Histological procedures. After completion of behavioral testing, each rat was deeply anesthetized and perfused transcardially with an aqueous solution of $10 \%(\mathrm{v} / \mathrm{v})$ formalin in $0.9 \%(\mathrm{w} / \mathrm{v}) \mathrm{NaCl}$ for $10-20 \mathrm{~min}$. The brains were removed, postfixed for at least $10 \mathrm{~d}$ in same solution, and were embedded and prepared for cresyl staining and histological analysis according to previously published methods (Cavazos et al., 1994). Electrode placement in the olfactory bulb was confirmed by visual inspection of the brain after removal and by histological analysis.

Statistical procedures. Differences between the kindled and matched control groups were reported as the mean \pm SEM. Parametric statistical tests were not employed because preliminary analysis with the Kolmogorov-Smirnov test revealed that the data did not conform to a normal distribution. Differences were therefore analyzed for statistical significance by the Kruskal-Wallis nonparametric analysis of variance and the Mann-Whitney rank sum test.

\section{Results}

A total of 32 pairs of kindled and control rats completed the study. The kindled rats had a mean initial AD threshold of 648 $\pm 35 \mu$ amps, experienced the first evoked Class V generalized tonic-clonic seizure after a mean of $5.9 \pm 0.4 \mathrm{ADs}$, and had a final $\mathrm{AD}$ threshold of $289 \pm 79 \mu$ amps. Six rats received twice daily stimulation that evoked three ADs. Of the remaining 26 kindled rats, six rats received twice daily stimulation that evoked three Class V seizures, five rats experienced 30 Class V seizures, 10 rats experienced $70-100$ Class $V$ seizures, and five rats experienced a total of 100-134 Class V seizures. There were no differences in initial AD thresholds or numbers of stimulations required to achieve the first Class V seizure among these groups.

There was no difference between the kindled and control groups in the number of daily trials required to achieve the first criterion performance of entering the four baited arms within the first five entries. The mean number of trials to the initial criterion performance was $10.4 \pm 0.8$ in the control group and $10.5 \pm$ 0.9 in the kindled group. There was no significant difference in motor performance of kindled and control rats, as indicated by the average time required to initially traverse an arm of the maze $(2.2 \pm 0.1 \mathrm{sec}$ in kindled versus $2.4 \pm 0.1 \mathrm{sec}$ in control rats, $p=0.35$ ).

Differences between the kindled and control groups emerged in the number of trials required to repeat the criterion performance on consecutive days $(H=11.66, d f=1, p=0.001$, Fig. 1). There were significant differences in the number of trials required to achieve three, four, and five consecutive criterion performances. Kindled rats required $25.4 \pm 2.1$ trials to achieve 3 consecutive days of criterion performance, but controls required only $20.7 \pm 2.2$ trials $(p=0.032)$. A total of $30.5 \pm 2.1$ trials were required by kindled rats to achieve 4 consecutive 


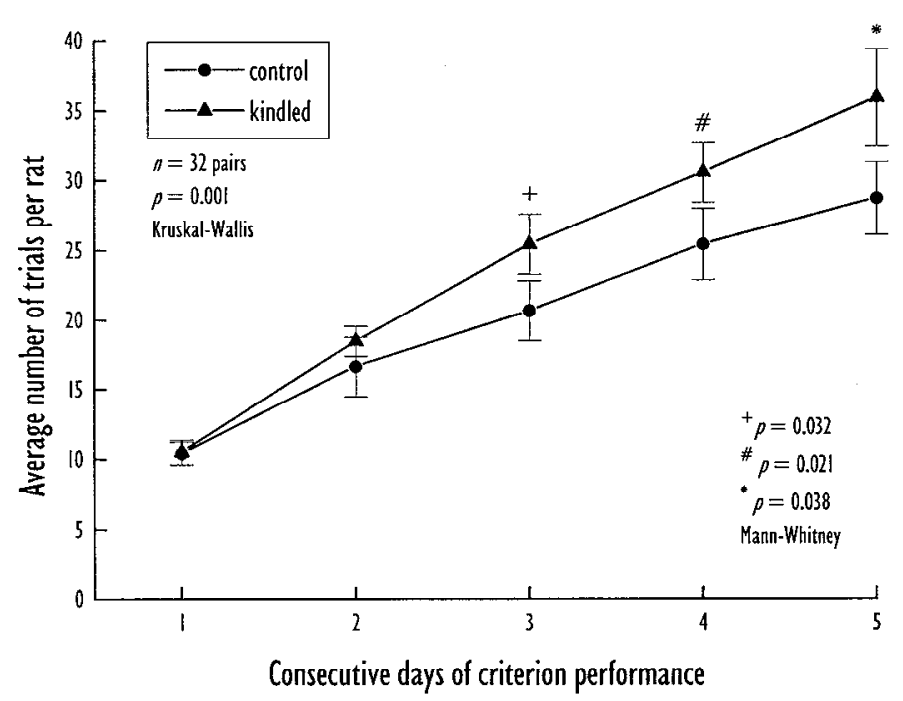

Figure I. Deficits in the repetition of criterion radial arm maze performance in kindled rats. Kindled rats required more daily trials to achieve three, four, and five consecutive criterion performances. Criterion performance was defined as consumption of the bait in the four baited arms of the radial maze during no more than five entries. There was no difference in the average number of trials required by kindled and control rats to achieve the initial criterion performance.

days of criterion performance, but controls required only 25.4 \pm 2.5 trials $(p=0.021)$. A total of $35.9 \pm 3.5$ trials were required by kindled rats to achieve 5 consecutive days of criterion performance, but controls required only $28.7 \pm 2.6$ trials $(p=0.038)$.

The control rat of the matched pairs completed the behavioral task of five consecutive criterion performances prior to its paired kindled rat in 15 of the 20 matched pairs that experienced 30 or more Class V seizures $(p=0.04$, sign test). Among the 12 matched pairs of kindled rats that experienced only three ADs or three Class $\mathrm{V}$ seizures, initial completion of the behavioral task of five consecutive criterion performances was evenly distributed between controls rats $(N=6)$ and kindled rats $(N=$ 6 ). This observation suggested that a performance deficit was present in kindled rats that experienced 30 or more Class V seizures, but was not present in kindled rats with three ADs or three Class V seizures.

Analysis of the number of trials required to repeat the criterion performance on consecutive days confirmed that there was no difference between the control and kindled groups with three $\Lambda \mathrm{Ds}$ and three Class $\mathrm{V}$ seizures $(H-3.55, d f-1, N S$, Fig. 2), but significant differences in the number of trials required to achieve four and five consecutive criterion performances were demonstrated in kindled rats that experienced 30 or more Class $\mathrm{V}$ seizures $(H=7.26, d f=1, p=0.007$, Fig. 3). Kindled rats with 30 or more Class $V$ seizures required $34.7 \pm 2.9$ trials to achieve 4 consecutive days of criterion performance, but controls required only $27.1 \pm 3.5$ trials $(p=0.014)$. A total of 41.1 \pm 4.8 trials were required by kindled rats to achieve 5 consecutive days of criterion performance, but controls required only $30.8 \pm 3.6$ trials $(p=0.017)$.

The additional trials required to achieve criterion performance on successive days in kindled rats with 30 or more Class $\mathrm{V}$ seizures were due to significantly more cumulative reference errors than in the normal controls (Fig. 4). The average number of reference errors per rat was similar in the control and kindled

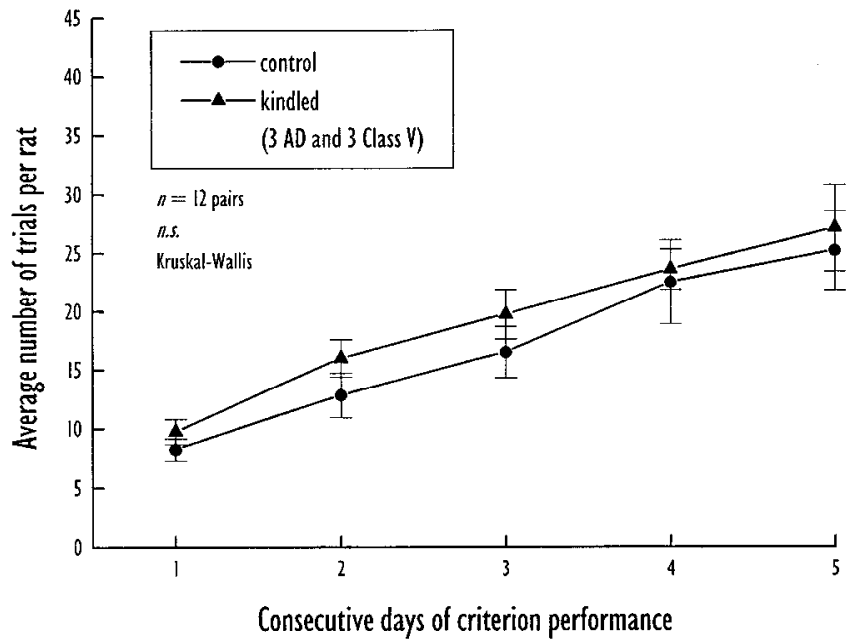

Figure 2. Deficits in the repetition of criterion radial arm maze performance were not observed in kindled rats that experienced only three afterdischarges or three Class $\mathrm{V}$ generalized tonic-clonic seizures. There was no difference in the average number of trials required by kindled and control rats to achieve the initial criterion performance.

groups to the stage of two consecutive criterion performances, but thereafter, reference errors were more frequently observed in the kindled rats than in controls. The number of reference errors committed by the kindled rats was directly proportional to the number of evoked ADs ( $r=0.69, p=0.00001$, Fig. 5). There was also a correlation of the number of references errors with the number of evoked generalized tonic-clonic seizures ( $r$ $=0.70, p<0.0001$, data not shown). There were no significant differences in working errors in control and kindled rats (Fig. $6)$.

Although there were differences in the number of trials required to achieve four and five consecutive criterion performances, all kindled and control rats eventually learned to correctly complete the task of entering the four baited arms within

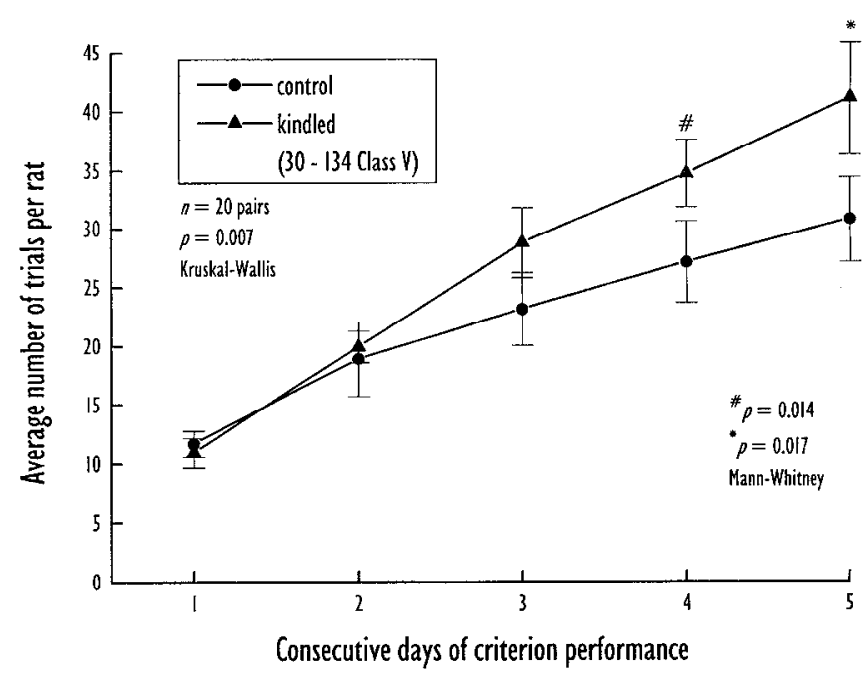

Figure 3. Deficits in the repetition of criterion radial arm maze performance were observed in kindled rats that experienced 30 or more Class $\mathrm{V}$ generalized tonic-clonic seizures. These kindled rats required more daily trials to achieve four and five consecutive criterion performances. There was no difference in the average number of trials required by kindled and control rats to achieve the initial criterion performance. 


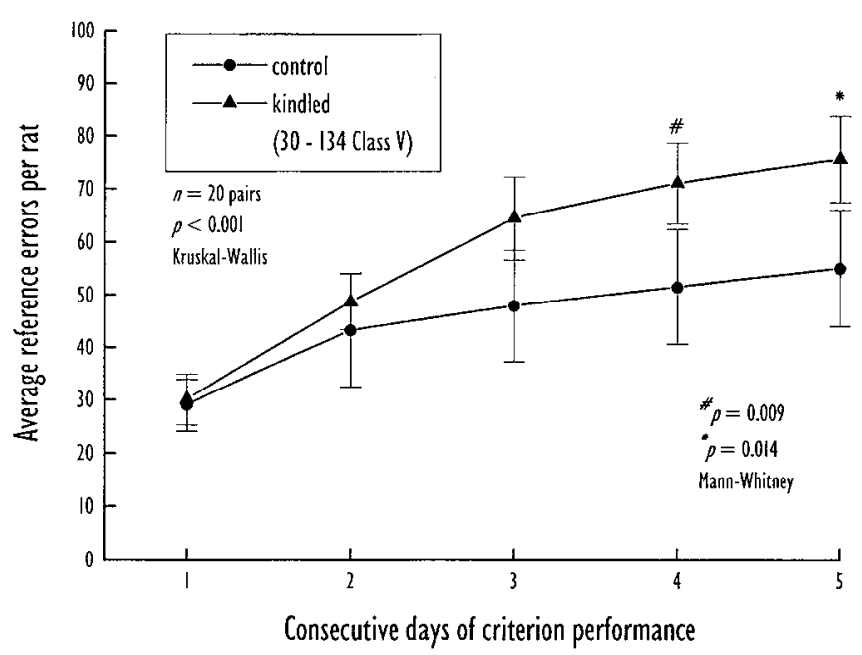

Figure 4. In kindled rats that experienced 30 or more Class $\mathrm{V}$ generalized tonic-clonic seizures, the additional trials required by to achieve consecutive criterion performances were due to additional reference errors, which were defined as entry into an unbaited arm.

five attempts on 5 consecutive days. Additional evidence that the kindled and control groups both successfully learned the task was demonstrated by preference for entry into previously baited arms when placed in the unbaited maze at 1 week after 5 consecutive days of criterion performance. At this time, rats in both the kindled and control groups entered previously baited arms more frequently than the unbaited arms. The ratio of entries into previously baited versus unbaited arms was $1.9 \pm 0.1$ in the kindled group, and $1.8 \pm 0.1$ in the control group. The preferences for entry into baited arms in both kindled and control rats were significantly different from the expected ratio of 1.0 for random choices ( $p=0.0001$, Student's $t$ test).

\section{Discussion}

This study revealed quantitative performance deficits in kindled rats in a radial arm maze behavior that is impaired by hippocampal damage. Kindled rats acquired competence in the initial performance of a radial arm maze task at a rate that was comparable to age-matched unstimulated normal controls, but demonstrated an impairment in the ability to consistently repeat the task in consecutive trials. The results demonstrated that the longterm alterations induced by kindling, which include hippocampal neuronal loss and mossy fiber sprouting in the dentate gyrus, were accompanied by significant behavioral deficits. These observations in kindled rats suggest that long-lasting cellular alterations induced by seizures in the hippocampus could contribute to memory dysfunction in human epilepsy.

\section{Features of the behavioral impairment in kindled rats}

There were no significant differences between kindled and control rats in overall activity or motor performance measured by average time required to initially traverse an arm of the maze. As the number of trials required by kindled rats to initially enter the four baitcd arms within five attempts did not differ from normal rats, any sensory or motor impairments that may have been induced by kindled seizures did not impair the ability to acquire competence in the radial arm maze task.

There was a clear difference, however, in the ability of kindled rats to repeat the criterion performance on consecutive days. As there was no evidence of a motor deficit in kindled rats, this

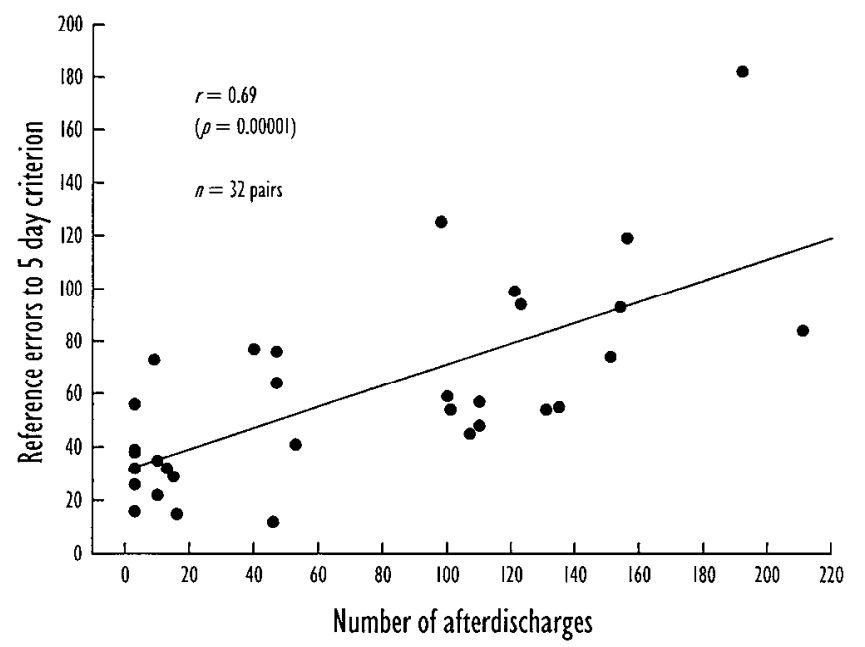

Figure 5. Scatter plot of the number of reference errors by each kindled rat as a function of the number of afterdischarges. Rats that experienced greater numbers of afterdischarges made more reference errors during radial arm maze testing $(r=0.69, p=0.00001)$.

difference suggested a deficit in the ability to store or retrieve recently acquired information that was used in preceding performances of the radial arm maze task. The deficit was most obvious in the number of trials required to achieve five consecutive criterion performances, but was also demonstrated by the additional trials required by kindled rats to complete three and four consecutive criterion performances.

Several additional aspects of the results supported the interpretation that the observed differences between kindled and normal rats were due to a defect in storage or retrieval of recently acquired information, rather than deficits in sensory, motor, or cognitive functions that were required for successful completion of the task. Despite the greater number of trials required hy the kindled rats to consecutively repeat the criterion performance, all kindled rats eventually did achieve five consecutive criterion performances. As the additional testing in an unbaited maze demonstrated comparable strong preferences for entry into pre-

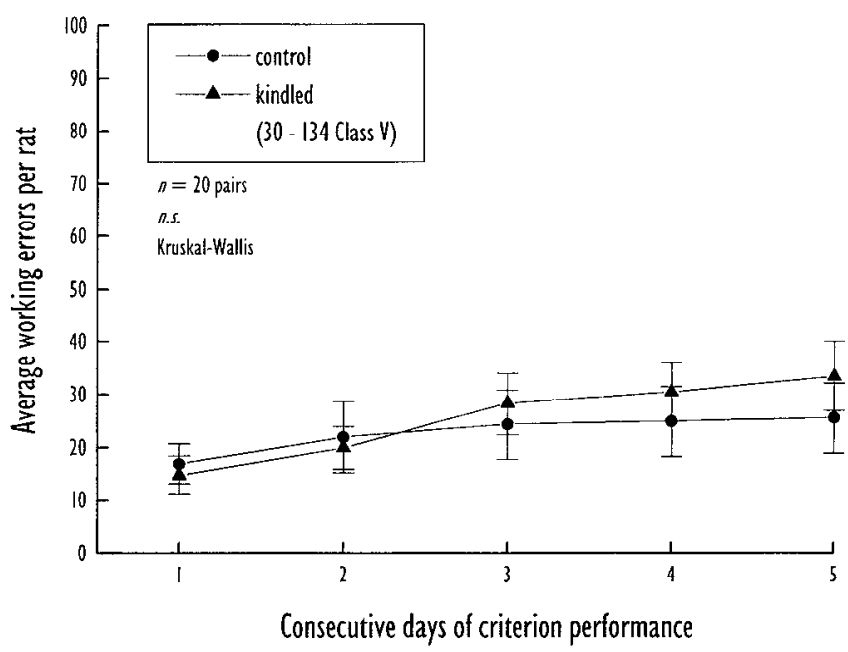

Figure 6. There were no significant differences between kindled and control rats in the number of working errors, which were defined as reentry into a previously visited arm of the maze during each daily trial. Reentry into an unbaited arm was scored as a reference and working error 
viously baited arms by both kindled and control rats, it is unlikely that enhanced sensitivity to olfactory cues from the bait accounted for the superior performance of the control rats.

From the design of this study, which evaluated radial arm performance for 2-3 months following a 1 month rest interval after the last evoked seizure, it can be concluded that deficits induced by repeated seizures persisted for as long as 4 months. $\Lambda$ dditional studies that begin radial arm maze testing at rest periods of greater that 1 month after the last evoked seizure could provide more information about the duration of the performance deficit. Because of the long intervals required to prepare and test highly kindled rats in these paragdigms, aging effects will be an interpretive issue in behavioral testing that extends for longer periods. In the current experiments, the potential contribution of aging effects was excluded by use of age-matched paired controls.

\section{Radial arm maze performance deficits and memory}

The additional trials required by kindled rats to achieve consecutive criterion performances were due to entries into unbaited arms, which were defined as reference errors. There was no difference between kindled and normal rats in working errors, defined as reentry into arms previously entered during the same trial. In previous studies of radial arm maze behavior in rodents, working errors have sometimes been regarded as "short-term" memory deficits. Reference errors have been regarded as evidence of "long-term" memory deficits (Lopes da Silva et al., 1986; Leung et al., 1990).

Although the interpretation of these errors as evidence of "short-term" or "long-term" memory deficits is at least in part a matter of definition or convention, the design and results of this study permitted relatively precise characterization of the temporal features of the radial arm maze impairment in kindled rats. The observation that kindled rats achieved the initial criterion performance at a rate that was indistinguishable from controls provides evidence that procedural learning in the maze, defined as the process of learning how to search for food, was unaffected by kindling. This observation was of interest, since humans with temporal lobe amnesia have preserved procedural memory (Squire and Zola-Morgan, 1991).

As there was no difference in the tendency of both kindled and control rats to reenter already visited arms during the same trial, it can be concluded that the underlying neural mechanisms for storage and retrieval of recently visited locations during the 10 min time interval of a testing session were not disrupted by kindling to stages of 30-134 Class $\mathrm{V}$ seizures. The difficulty encountered by kindled rats in repeating the procedure $24 \mathrm{hr}$ later is consistent with the possibility that kindling selectively disrupted neural mechanisms which play a role in storage or retrieval of this information during this $24 \mathrm{hr}$ interval. The characterization of the time course of the deficit revealed in this study may be pertinent to concepts of "short-term" and "longterm" memory, and the "medial temporal lobe memory system" (Squire and Zola-Morgan, 1991; Zola-Morgan and Squire, 1993).

\section{Kindled seizures as cause of the performance deficit}

There was a direct relationship between the number of evoked ADs and cumulative reference errors in each rat. Rats that experienced the largest numbers of evoked seizures had the most severe deficits, as indicated by higher numbers of reference errors. This observation implied that there was a causal relation- ship between the kindled seizures and the behavioral deficit, but the specific contributions of the many long-lasting cellular alterations induced by kindling (Sutula et al., 1992) to the performance deficit in radial arm maze were uncertain.

In previous radial arm maze studies in kindled rats, transient impairments in working and reference memory have been detected at 2-24 hr after Class V seizures (Lopes de Silva et al., 1986; Leung et al., 1990; Feasy-Truger et al., 1993), but reference memory impairments recovered by $21 \mathrm{~d}$ after 12 Class V seizures (Feasy-Truger et al., 1993). Other studies of spatial memory assessed by the Morris water maze have not revealed impairments at $24 \mathrm{hr}$ after six kindled generalized tonic-clonic seizures (McNamara et al., 1992), or at $20 \mathrm{~d}$ after 20 evoked generalized tonic-clonic seizures (Holmes et al., 1993). In this study, the deficit in radial arm maze performance was observed as long as 4 months after about 40 ADs or 30 evoked Class V seizures.

\section{Kindling, hippocampal sclerosis, and memory disorders}

Previous studies in the kindling model have demonstrated that brief, repeated seizures evoked by kindling induce a specific pattern of hippocampal and limbic neuronal loss, that progresses in parallel with the number of evoked seizures, and resembles hippocampal sclerosis (Cavazos et al., 1990, 1994). There is a close correlation between brief, repeated kindled seizures and progressive loss of neurons in the hilus of the dentate gyrus, CA3, CA1, and other limbic structures (Cavazos et al., 1994). It is possible that seizure-induced neuronal loss in the hippocampus of kindled rats caused the deficits in radial arm maze performance, which is vulnerable to hippocampal damage (Jarrard, 1980; McNaughton et al., 1989).

The neuronal loss induced by kindling is initially most apparent in the hilus of the dentate gyrus, and gradually develops in CA1, CA3, and eventually in other limbic areas such as the endopyriform cortex and the entorhinal cortex. Although some neuronal loss also eventually occurs in CA2 and the granule cell layer of the dentate gyrus, these regions are relatively resistant to excitotoxic injury and are relatively spared (Cavazos et al., 1994). The predictable, regionally specific progressive features of seizure-induced neuronal loss in the kindled rats may be useful to investigate the behavioral effects of relatively subtle, welldefined hippocampal lesions. Studies using quantitative stereological methods to assess the relationship between seizure-induced hippocampal neuronal loss and the performance deficit the radial arm maze are in progress.

There is remarkable correspondence between the long-lasting cellular alterations induced by kindling and pathological abnormalities that are frequently observed in the human epileptic temporal lobe, which include hippocampal neuronal loss (Babb and Brown, 1987; Gloor, 1993) and mossy fiber sprouting (deLanerolle et al., 1989; Represa et al., 1989; Sutula et al., 1989; Houser et al., 1990). The pattern of neuronal loss induced by brief, repeated kindled seizures (Cavazos et al., 1994) closely resembles hippocanpal sclerosis, which is characterized by neuronal loss and gliosis in the hilus of the dentate gyrus, CA1, and CA3, and is the most common lesion observed in human epilepsy (Babb and Brown, 1987; Gloor, 1993). In people with temporal lobe epilepsy, the CA2 region and the granule cells of the dentate gyrus are often relatively spared, but in some cases there is neuronal loss in all regions of the hippocampal formation, including extrahippocampal limbic cortex (Kim et al., 1990). Thus, patterns of selective vulnerability and the extreme 
range of widespread neuronal loss observed in human temporal lobe epilepsy can be induced by repeated kindled seizures.

Memory impairment is also common in people with temporal lobe epilepsy, but it has been difficult to determine if the memory deficits are an intrinsic feature of temporal lobe epilepsy, or are effects of treatment with potentially sedating anticonvulsants or underlying primary pathological lesions. Despite these confounding variables, tests of memory in people who have undergone temporal lobectomy for treatment of seizures have demonstrated a negative correlation between preoperative measures of verbal memory impairment and neuronal density in CA3 and the hilus of the dentate gyrus (Sass et al., 1990). Additional evidence of a relationship between memory dysfunction and hippocampal neuronal loss includes the observation that patients with mild or no preoperative memory deficit showed only mild or no hippocampal sclerosis in postsurgical pathological analysis, but were at risk for increased memory dysfunction after surgery (Hermann et al, 1992). This latter observation suggested that removal of relatively normal hippocampus interfered with learning and memory.

In the context of these clinical observations, the demonstration in this study of an acquired deficit in radial arm maze performance in kindled rats is of potential significance. The direct correlation of the severity of the performance deficit with increasing numbers of evoked seizures suggests that seizure-induced hippocampal neuronal loss may cause an incremental, progressive memory deficit. The repetition deficit observed in kindled rats was remarkably similar to memory problems in people with temporal lobe epilepsy, who perform relatively well in tests of short-term memory, but perform less well or poorly in measures that assess ability to enter new information into longterm memory (for a review, see Chelune, 1995). These observations in kindled rats suggest that seizures in people may also induce hippocampal sclerosis and memory dysfunction.

There is considerable experimental and clinical evidence that intense, continuous seizure activity as in status epilepticus induces excitotoxic neuronal loss and long-term cognitive impairment (Meldrum et al., 1973; Hauser et al., 1983; Dodrill, 1986; Sloviter, 1987). This study, in addition, suggests that brief, repeated seizures induce long-lasting defects in the medial temporal lobe memory system. These disturbing observations, and the evidence that long-term structiural and functional effects of seizures can be modified by therapeutic intervention (Sutula et al., 1992), emphasize the potentially devastating consequences of uncontrolled seizures, and the urgent needs for development of prompt effective therapeutic intervention, fundamental insights, and improved treatment of this common disorder.

\section{References}

Babb T, Brown W (1987) Pathological findings in epilepsy. In: Surgical treatment of the epilepsies (Engel J, ed), pp 511-540. New York: Raven.

Cavazos JE, Sutula T (1990) Progressive neuronal loss induced by kindling: a possible mechanism for mossy fiber synaptic reorganization and hippocampal sclerosis. Brain Res 527:1-6.

Cavazos J, Golarai G, Sutula T (1991) Mossy fiber synaptic reorganization induced by kindling: time course of development, progression, and permanence. J Neurosci 11:2795-2803.

Cavazos J, Das I, Sutula T (1994) Neuronal loss induced in limbic pathways by kindling: evidence for induction of hippocampal sclerosis by brief repeated seizures. J Neurosci 14(5):3106-3121.

Chelune G (1995) Hippocampal adequacy versus functional reserve: predicting memory functions following temporal lohectomy. Arch Clin Neuropsychol, in press.

de Lanerolle N, Kim J, Robbins R, Spencer D (1989) Hippocampal interneuron loss and plasticity in human temporal lobe epilepsy. Brain Res 495:387-395.

Dodrill CB (1986) Correlates of generalized tonic clonic seizures with intellectual, neuropsychological, enotional, and social functions in patients with epilepsy. Epilepsia 27:399-411.

Eichenbaum H, Otto T, Cohen N (1992) The hippocampus-what does it do? Behav Neural Biol 57:2-36.

Feasy-Truger KJ, Kargl L, ten Bruggencate G (1993) Differential effects of dentate kindling on working and reference spatial memory in the rat. Neurosci Lett 151:25-28.

Gloor P (1991) Mesial temporal sclerosis: historical background and an overview from a modern prospective. In: Epilepsy surgery (Luders $\mathrm{H}$, ed), pp 689-703. New York: Raven.

Goddard G, McIntyre D, Leech C (1969) A permanent change in brain function resulting from daily clectrical stimulation. Exp Neurol 25 . 295-330.

Hauser WA (1983) Status epilepticus: frequency, etiology, and neurological sequelae. Adv Neurol 34:3-14.

Hermann B, Wyler A, Somes G, Berry A, Dohan F (1992) Pathological status of the mesial temporal lobe predicts memory outcome from left anterior temporal lobectomy. Neurosurgery 31:652-657.

Holmes G, Chronopoulos A, Stafstrom C, Mikati M, Thurber S, Hyde P, Thompson J (1993) Effects of kindling on subsequent learning, memory, behavior, and seizure susceptbility. Dev Brain Res 73:7177.

Houser C, Miyashiro J, Swartz B, Walsh G, Rich J, Delgado Escueta AV (1990) Altered patterns of dynorphin immunoreactivity suggest mossy fiber reorganization in human hippocampal epilepsy. J Neurosci 10:276-282.

Jarrard L (1980) Selective hippocampal lesions and behavior. Physiol Psychol 8:198-206.

Jarrard L (1993) On the role of the hippocampus in learning and memory in the rat. Behav Neural Biol 60:9-26.

Kim J, Guimaraes PO, Shen MY, Masukawa LM, Spencer D (1990) Hippocampal neuronal density in temporal lobe epilepsy with and without gliomas. Acta Neuropathol 80:41-45.

Knowlton B, McGowan M, Olton D (1985) Hippocampal stimulation disrupts spatial working memory even $8 \mathrm{~h}$ after acquisition. Behav Neurol Biol 44:325-337.

Knowlton B, Shapiro ML, Olton D (1989) Ilippocampal seizures disrupt working memory performance but not reference memory acquisition. Behav Neurosci 103:1144-1147.

Leung LS, Boon KA, Kaibara T, Innis NK (1990) Radial maze performance following hippocampal kindling. Behav Brain Res 40:119 129.

Lopes Da Silva FH, Gorter JA, Wadman WJ (1986) Kindling of the hippocampus induces spatial memory deficits in the rat. Neurosci Lett 63:115-120.

McNamara J (1986) The kindling model of epilepsy. Adv Neurol 44: 303-318.

McNamara RK, Hirkby RD, dePape GE, Corcoran ME (1992) Limbic seizures, but not kindling, reversibly impair place learning in the Morris water maze. Behav Brain Res 50:167-175.

McNaughton BL, Barnes CA, Meltzer J, Sutherland RJ (1989) Hippocampal granule cells are necessary for normal spatial learning but not spatially-selective pyramidal cell discharge. Exp Brain Res 76: 485-496.

Meldrum B, Vigouroux R, Brierley J (1973) Systemic factors and epileptic brain damage: prolonged seizures in paralyzed artificially ventiliated baboons. Arch Neurol Psychôl 29:82-87.

Morris RG, Garrud P, Rawlins JN, O'Keefe J (1982) Place navigation impaired in rats with hippocampal lesions. Nature 297:681-683.

Moser E, Moser MB, Andersen P (1993) Spatial learning impairment parallels the magnitude of dorsal hippocampal lesions, but is hardly present following ventral lesions. J Neurosci 13:3916-3925.

Muller RU, Kubie JL, Ranck JB (1987). Spatial firing patterns of hippocampal complex spike cells in a fixed environment. J Neurosci 7:1935-1950.

O'Keefe J (1990) A computational theory of the cognitive map. Prog Brain Res 83:301-312.

O'Keefe J, Nadel L (1978) The hippocampus as a cognitive map. Oxford: Clarendon.

Quirk GJ, Muller RV, Kubie IL (1990) The firing of hippocampal place in the dark depends on the rat's recent experience. J Neurosci 10: 2008-2017. 
Represa A, Robain O, Tremblay E, Ben-Ari Y (1989) Hippocampal plasticity in childhood epilepsy. Neurosci Lett 99:351-355.

Sass K, Spencer D, Kin J, Westerveld M, Novelly R, Lencz B (1990) Verbal memory impairment correlates with hippocampal pyramidal cell density. Neurology 40:1694-1697.

Scoville W, Milner B (1957) Loss of recent memory after recent bilateral hippocampal lesions. J Neurol Neurosurg Psychiatry 20:1121.

Sloviter R (1987) Decreased hippocampal inhibition and a selective loss of interneurons in experimental epilepsy. Science 235:73-75.

Squire L (1992) Memory and the hippocampus a synthesis from findings with rats, monkeys, and humans. Psychol Rev 99:195-231.

Squire L, Zola-Morgan S (1991) The medial temporal lobe memory system. Science 253:1380-1386.

Squire L, Amaral D, Press G (1990) Magnetic resonance imaging of the hippocampal formation and mammillary nuclei distinguish medial temporal lobe and diencephalic amnesia. J Neurosci 10:3106-3117.

Sutula T, Steward O (1986) Quantitative Analysis of swynaptic potentiation during kindling of the perforant path. J Neurophysiol 56:732 745.

Sutula T, He XX, Cavazos J, Scott G (1988) Synaptic reorganization in the hippocampus induced by abnormal functional activity. Science 239:1147-1150.
Sutula T, Cascino G, Cavazos J, Parada I, Ramirez L (1989) Mossy fiber synaptic reorganization in the epileptic human temporal lobe. Ann Neurol 26:321-330.

Sutula T, Cavazos J, Golarai G (1992) Alteration of long-lasting structural and functional effects of kainic acid in the hippocampus by brief treatment with phenobarbital. J Neurosci 12:4173-4187.

Sutula T, Golarai G, Cavazos J (1992) Assessing the functional significance of mossy fiber sprouting. Epilepsy Res Suppl 7:251-259.

Sutula T, Cavazos J, Woodard A (1994) Long-term structural and functional alterations induced in the hippocampus by kindling: implications for memory dysfunction and the development of epilepsy. Hippocampus 4:254-258.

Treves A, Rolls ET (1994) Computational analysis of the role of the hippocampus in memory. Hippocampus 4:374-391.

Zola-Morgan S, Squire L (1990) The primate hippocampal formation-evidence for a time-limited role in memory storage. Science 250:288-290.

Zola-Morgan S, Squire LR (1993) Neuroanatomy of memory. Annu Rev Neurosci 16:547-563.

Zola-Morgan S, Squire L, Amaral D (1989) Lesions of the amygdala that spare adjacent cortical regions do not impair memory or exacerbate the impairment following lesions of the hippocampal formation. J Neurosci 9:1922-1963. 